Pengembangan Rekayasa dan Teknologi, Vol 13, No. 2, Desember 2017, pp 33-36

p-ISSN: 1410-9840 \& e-ISSN: 2580-8850

http://journals.usm.ac.id/index.php/jprt/index

\title{
EKSTRAKSI ANTOSIANIN KULIT MELINJO MERAH DAN STABILITAS WARNANYA PADA BERBAGAI LAMA PEMANASAN
}

\author{
${ }^{1}$ Elly Yuniarti Sani dan ${ }^{2}$ Bambang Kunarto \\ ${ }^{1,2}$ Program Studi Teknologi Hasil Pertania, Jurusan Teknologi Hasil Pertanian \\ Fakultas Teknologi Pertanian, Universitas Semarang \\ ${ }^{1}$ Ellyys59@gmail.com
}

\begin{abstract}
ABSTRAK
Pigmen merah antosianin kulit melinjo bersifat antioksidan dan lebih aman dibandingkan dengan pigmen sintetik. Untuk mengekstraksi pigmen antosianin kulit melinjo perlu dipilih pelarut yang aman dan menghasilkan rendemen tinggi dengan kualitas warna dan aktivitas antioksidan yang baik. Tujuan penelitian ini adalah untuk mengekstrak antosianin kulit melinjo merah menggunakan berbagai rasio etanol: air dan mengetahui stabilitas warna dan aktivitas antioksidatif antosianin pada berbagai lama pemanasan. Ekstraksi dilakukan menggunakan rasio pelarut etanol:air dengan perbandingan (100:0); (75:25); (50:50); (25:75); (0:100). Ekstrak antosianin dianalisis rendemen, antosianin dan aktifitas antioksidannya. Hasil terbaik dipakai sebagai penelitian tahap kedua dengan mengukur stabilitas warna antosianin dan aktivitas antioksidatifnya berbagai lama pemanasan (10, 20, 30, 40 dan 50 menit). Hasil penelitian menunjukkan bahwa pelarut etanol dan air dengan rasio (100:0)) menghasilkan ekstrak antosianin kulit melinjo merah terbaik dengan rendemen $\mathbf{1 2 , 9 5 \%}$, kadar total antosianin $\mathbf{4 3 , 5 2} \mathrm{mg} / \mathrm{L}$ dan aktivitas antioksidan (penghambatan DPPH) 66,29\%. Ekstrak antosianin kulit merah antosianin stabil pemanasan 10-30 menit.
\end{abstract}

Kata kunci: Kulit melinjo merah, antosianin, antioksidan

\begin{abstract}
The objective of this study was to extract anthocyanin from melinjo peels and it's stability in various heating periods. Extraction was performed using ethanol solvent ratio: water with ratio (100: 0); (75:25); (50:50); (25:75); (0: 100). Anthocyanin extracts were analyzed yield, anthocyanin and antioxidant activity. The results showed that ethanol and water solvent with ratio (100: 0)) was the best treatment with $12.95 \%$ yield, total anthocyanin content of $43.52 \mathrm{mg} / \mathrm{L}$ and antioxidant activity (DPPH inhibition) 66.29\%. anthocyanin extract is stable heating 10-30 minutes.
\end{abstract}

Keywords: red melinjo peels, anthocyanin, antioxidant

\section{PENDAHULUAN}

Sampai saat ini penggunaan bahan pewarna dan antioksidan sintetik untuk makanan dan minuman masih dominan, selain harganya lebih murah, proses produksinya juga lebih cepat dan lebih stabil dibandingkan dengan bahan pewarna alami yang umumnya berasal dari tanaman. Akan tetapi, banyak hasil penelitian membuktikan bahwa beberapa bahan pewarna sintetik maupun antioksidan sintetik berbahaya bagi kesehatan sehingga tidak aman untuk dikonsumsi. Oleh karena itu dewasa ini banyak diteliti sumber pigmen alami yang lebih aman dikonsumsi, salah satunya adalah kulit melinjo yang mengandung pigmen antosianin berwarna merah. Disamping sebagai pewarna, antosianin juga bersifat antioksidan karena termasuk golongan flavonoid yang efektif untuk inaktivasi radikal bebas dan peroksil.

Devina (2011) dan Suwito (2011) telah meneliti bahwa kulit buah melinjo berpotensi sebagai sumber antioksidan. Kulit melinjo merah yang diekstrak oleh Devina (2011) menggunakan pelarut etanol dan etil asetat $(20: 80)$ pada suhu $30^{\circ} \mathrm{C}$ selama 3 jam mempunyai aktivitas antioksidan 1723,231 ppm, mengandung beta karoten 255,20 ppm, total fenol $11,805 \mathrm{mg} \mathrm{GAE} / \mathrm{mg}$ ekstrak dan vitamin C 1,153 mg/g ektrak. Sedangkan Optimasi antioksidan yang dilakukan oleh Suwito (2011) menggunakan response surface methodology pada kombinasi $\mathrm{pH}$ 4,75 dan suhu $43,79^{\circ} \mathrm{C}$ adalah $571,64 \mathrm{ppm}$. Kandungan fitokimia kulit melinjo merah yang digunakan oleh Kunarto dan Pratiwi (2014) adalah kadar fenolat 18,64 mg GAE/g ekstrak, kadar flavonoid $15,83 \mathrm{mg}$ QE/g ekstrak, likopen 248,9 mg/kg, beta karoten 25,96 mg/100g dan vitamin C 53,35 mg/100g. Berdasarkan perhitungan prosentase penangkapan radikal bebas menunjukkan bahwa kulit melinjo merah mempunyai aktivitas antioksidan 61,0875\%. Diharapkan antosianin kulit melinjo merah dapat dipakai sebagai pigmen dan antioksidan alami pada pangan yang cukup aman karena penggunaan antioksidan sintetis (BHA, BHT, TBHQ dan PG) dalam proses pengolahan pangan telah banyak menimbulkan kekhawatiran akan efek sampingnya 
Menurut Khuluk dkk (2007) pelarut yang sesuai untuk ekstraksi antosianin adalah metanol $80 \%$, namun berbahaya jika diaplikasikan ke pangan. Untuk itu perlu dikaji pelarut lain yang lebih aman. Pada penelitian ini akan digunakan kombinasi pelarut etanol dan air. Diharapkan penggunaan kombinasi pelarut tersebut yang bertitik didih rendah akan efektif dalam melarutkan dan dapat berinteraksi positif dalam menghasilkan ekstrak antosianin kulit melinjo merah dengan kualitas baik dan mempunyai sifat antioskidan yang tingi.

Kestabilan pigmen antosianin sangat dipengaruhi oleh faktor fisik maupun kimia seperti temperatur, sinar (light), dan oksigen serta faktor lainnya seperti enzim dan logam, dan umumnya antosianin lebih stabil dalam kondisi asam, media bebas oksigen dan dalam kondisi suhu dingin dan gelap.

Tujuan penelitian ini adalah untuk mengekstrak antosianin kulit melinjo menggunakan berbagai rasio etanol: air dan mengetahui stabilitas warna dan aktivitas antioksidatif antosianin pada berbagai lama pemanasan.

\section{METODE}

Bahan baku pada penelitian ini adalah kulit melinjo merah berumur 4 bulan yang diperoleh dari petani melinjo daerah Limpung. Bahan kimia antara lain aquabides, etanol, asam asetat, $\mathrm{NaCO}_{3}, \mathrm{NaNO}_{3}$, $\mathrm{AlCl}_{3}, \mathrm{NaOH}, \mathrm{DPPH}$ (2,2-diphenyl-1 picrylyhdrazil) dan folin ciocalteu's. Beberapa peralatan yang dipergunakan adalah baker glass, blander, waterbath, spektrofotometer dan beberapa peralatan gelas untuk analisis.

Penelitian ini dibagi menjadi dua tahap, yaitu ekstraksi antosianin kulit melinjo dan menguji stabilitas warna antosianin dan aktivitas antioksidatifnya. Ekstraksi dilakukan menggunakan rasio pelarut etanol:air dengan perbandingan (100:0); (75:25); (50:50); (25:75); (0:100). Ekstrak antosianin dianalisis rendemen, antosianin dan aktifitas antioksidannya. Hasil terbaik dipakai sebagai penelitian tahap kedua dengan mengukur stabilitas warna antosianin dan aktivitas antioksidatifnya berbagai lama pemanasan $(10,20,30$, 40 dan 50 menit). Stabilitas warna diukur absorbansinya pada panjang gelombang $517 \mathrm{~nm}$. Sedangkan aktivitas antioksidatifnya diukur menggunakan DPPH

Rancangan percobaan yang digunakan adalah rancangan acak lengkap satu factor dan 3 kali ulangan. Perlakuannya adalah sebagai berikut: $\mathrm{A} 1=$ rasio etanol: air (100:0); A2= rasio etanol: air (75:25); $\mathrm{A} 3=$ rasio etanol: air (50:50); $\mathrm{A} 4=$ rasio etanol: air (25:75); $\mathrm{A} 5=$ rasio etanol: air (0:100). Sedangkan perlakuan untuk stabilitas adalah:B1= lama pemanasan 10 menit, B2= lama pemanasan 20 menit, B3= lama pemanasan 30 menit, B4= lama pemanasan 40 menit, B5= lama pemanasan 50 menit. Analisa statistik dilanjutkan dengan uji lanjutan (DMRT) pada taraf 5\% untuk mengetahui perbedaan masing -masing taraf perlakuan.

\section{HASIL DAN PEMBAHASAN}

\section{Rendemen ekstrak kulit melinjo merah}

Rendemen ekstrak kulit melinjo merah berkisar antara 7,29\%-12,93\% (Gambar 1 dan Lampiran 1). Secara statistik menunjukkan bahwa perlakuan rasio pelarut (etanol:air) berpengaruh nyata $(\mathrm{p}<0,05)$ pada rendemen yang dihasilkan. Semakin banyak proporsi air menunjukan rendemen yang semakin rendah. Besarnya rendemen ekstrak ini terkait dengan derajad kepolaran pelarut yang digunakan. Kelarutan zat dalam pelarut dipengaruhi oleh kecocokan sifat antara zat terlarut dengan pelarut, yaitu sifat like disolve like berdasarkan derajad kepolarannya. Pelarut etanol:air (100:0) menghasilkan ekstrak tertinggi, yaitu $12.93 \%$

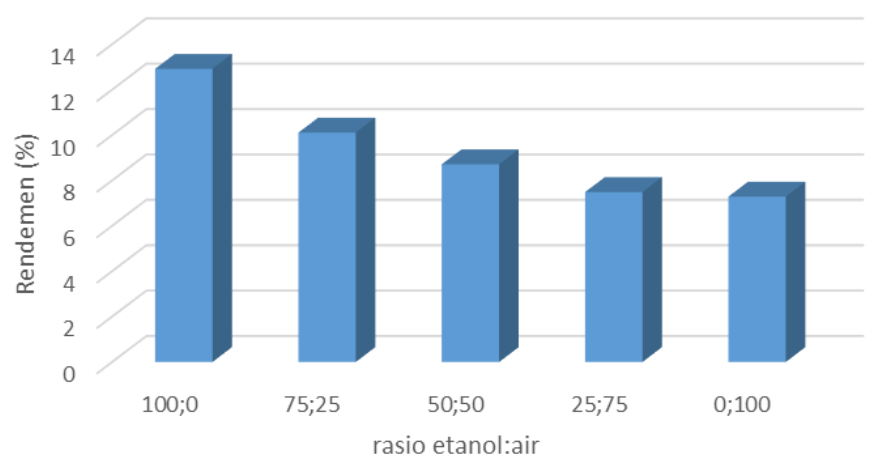

Gambar 1. Rendeman ekstrak kulit melinjo merah

\section{Antosianin ekstrak kulit melinjo merah}

Perlakuan berbagai rasio pelarut (etanol:air) menunjukkan berbeda nyata $(\mathrm{p}<0,05)$ terhadap total antosianin ekstrak kulit melinjo merah dan berkisar antara 10,64-43,52 mg/L. Grafik hubungan berbagai rasio pelarut terhadap total antosianin ekstrak kulit melinjo merah ditunjukan pada Gambar 2.

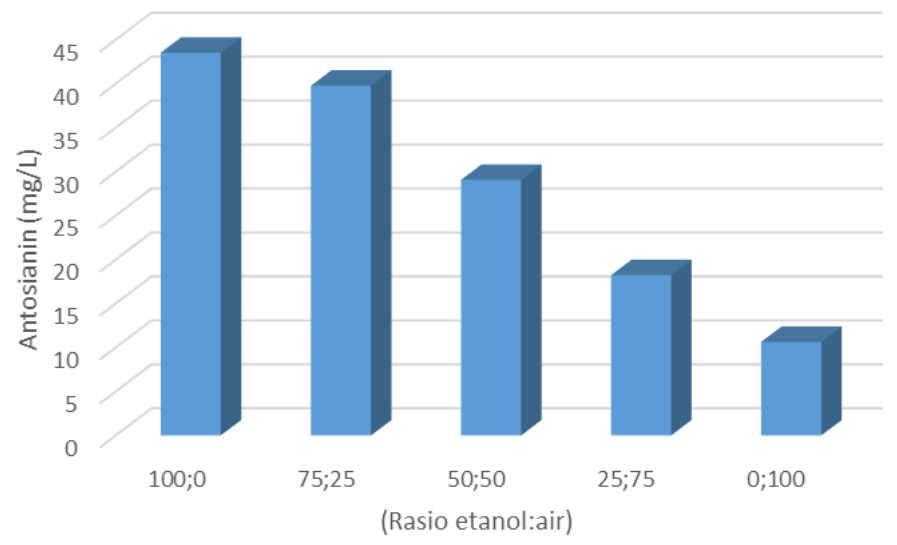

Gambar 2. Total antosianin ekstrak kulit melinjo merah

Pada Gambar 2 ditunjukkan bahwa semakin sedikit proporsi air dan semakin banyak proporsi etanol pada komponen pelarut menunjukkan total antosianin kulit melinjo merah semakin meningkat. Hal ini 
disebabkan karena tingkat kepolarannya mendekati tingkat kepolaran antosianin kulit melinjo merah. Hal ini didukung oleh Pujaatmaka (1986) bahwa kelarutan zat dalam pelarut dipengaruhi oleh kecocokan sifat antara zat terlarut dengan pelarut, yaitu sifat like disolve like berdasarkan derajad kepolarannya. Pada penelitian ini rasio pelarut etano:air (100:0) menghasilkan kadr antosianin tertinggi, yaitu $43,52 \mathrm{mg} / \mathrm{L}$

\section{Aktivitas antioksidan (\% pemerangkapan DPPH)}

Berbagai perlakuan rasio pelarut (etanol:air) menunjukan berpengaruh nyata $(p<0,05)$ terhadap aktivitas antioksidan ekstrak antosianin kulit melinjo merah dengan prosen pemerangkapan DPPH yang berkisar antara 25,19-66,29\%. Grafik hubungan berbagai rasio pelarut terhadap kapasitas antioksidan ekstrak pigmen antosianin kulit melinjo merah ditunjukan pada Gambar 3.

Ditunjukkan pada Gambar 3 bahwa semakin sedikit proporsi air dan semakin banyak proporsi etanol pada komponen pelarut menunjukkan aktivitas antioksidan ekstrak antosianin kulit melinjo merah semakin meningkat. Antosianin merupakan senyawa polifenol golongan flavonoid yang dapat berfungsi sebagai antioksidan yang efektif untuk inaktivasi radikal bebas dan peroksil. Antosianin dengan gugus hidroksi bebas mempunyai aktivitas dalam mengikat radikal bebas dan dengan adaya gugus hidroksil lebih dari satu terutama pada cincin B akan meningkatkan aktivitas antioksidannya (Muchtadi, 2009). Sesuai dengan Gambar 2 bahwa semakin banyak proporsi etanol dalam pelarut menunjukkan semakin tinggi antosianin maka kapasitas antioksidannya juga semakin meningkat. Aktivitas antioksidan terbaik pada penelitian ini adalah 66,29\% yang diperoleh dari ekstrak kulit melinjo merah menggunakan pelarut etanol air (100:0).

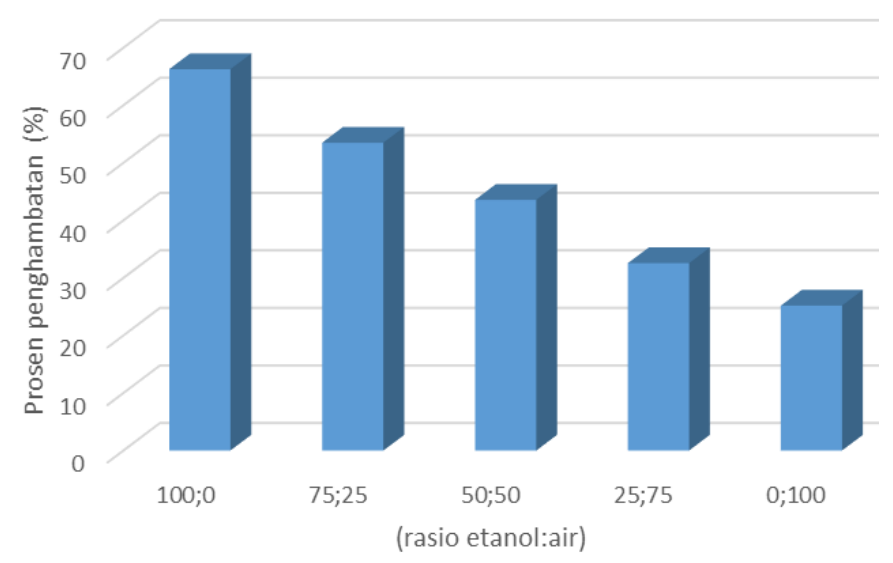

Gambar 3. Aktivitas antioksidan ekstrak kulit melinjo merah (\% pemerangkapan DPPH)

Berdasarkan hasil rendemen, antosianin dan aktivitas antioksidan menunjukan bahwa hasil terbaik adalah rasio pelarut etanol : air (100:0). Untuk itu pengukuran stabilitas dilakukan pada ekstrak kulit melinjo merah yang diekstrak menggunakan rasio pelarut etanol (100:0).

\section{Stabilitas ekstrak antosianin kulit melinjo merah pada berbagai lama pemanasan}

Perlakuan berbagai lama pemanasan terhadap stabilitas intensitas warna, kadar antosianin dan aktivitas antioksidan ekstrak ekstrak kulit melinjo merah ditunjukkan pada Tabel 1. Apabila dibandingkan dengan ekstrak kulit melinjo sebelum dipanaskan (Gambar 2 dan Gambar 3) menunjukkan bahwa pemanasan akan menurunkan kadar antosianin maupun aktivitas antioksidan.

Tabel. Pengaruh lama pemanasan terhadap stabilitas ekstrak

\begin{tabular}{llll}
\hline $\begin{array}{l}\text { Lama } \\
\text { pemanasan } \\
\text { (menit) }\end{array}$ & $\begin{array}{l}\text { Rerata } \\
\text { Intensitas } \\
\text { warna }\end{array}$ & $\begin{array}{l}\text { Rerata } \\
\text { Antosianin } \\
(\mathrm{mg} / \mathrm{L})\end{array}$ & $\begin{array}{l}\text { Rerata } \\
\text { Aktivitas } \\
\text { Antioksidan }(\% \\
\text { pemerangkapan } \\
\text { DPPH) }\end{array}$ \\
\hline 10 & & & $43,86^{\mathrm{c}}$ \\
20 & $56,42^{\mathrm{c}}$ & $30,32^{\mathrm{c}}$ & $42,35^{\mathrm{c}}$ \\
30 & $55,58^{\mathrm{c}}$ & $29,02^{\mathrm{c}}$ & $42,18^{\mathrm{c}}$ \\
40 & $54,58^{\mathrm{c}}$ & $28,97^{\mathrm{c}}$ & $32,38^{\mathrm{b}}$ \\
50 & $45,02^{\mathrm{b}}$ & $19,23^{\mathrm{b}}$ & $30,17^{\mathrm{a}}$ \\
\hline
\end{tabular}

Keterangan:

1. Hasil merupakan rerata dari tiga kali ulangan

2. Rerata kolom yang diikuti superskrip yang berbeda menunjukkan beda nyata $(\mathrm{p}<0,05)$

Berdasarkan perhitungan statistik menunjukkan bahwa berbagai lama pemanasan berpengaruh nyata $(\mathrm{p}<0,05)$ terhadap stabilitas ekstrak antosianin kulit melinjo (baik intensitas warna, kadar antosianin maupun aktivitas antioksidan). Pada pemanasan selama 10 menit, 20 menit dan 30 menit, ekstrak antisianin kulit melinjo merah masih stabil, namun pada pemanasan selama 40 dan 50 menit menunjukan penurunan stabilitas. Menurut Setyama (2008) degradasi antosianin juga dipengaruhi suhu. Semakin tinggi suhu, degradasi semakin meningkat. Semakin lama dipanaskan dimungkinkan terjadi peningkatan suhu.. Naiknya suhu akan menginduksi rusaknya struktur antosianin dengan mekanisme terjadinya hidrolisis ikatan glikosidik antosianin dan menghasilkan aglikom aglikon yang labil serta terbukanya cincin pirilium sehingga terbentuk cincin karbonol dan kalkon yang tidak berwarna. Semakin lama pemanasan akan terjadi akumulasi panas yang berakibat turunnya stabilitas antosianin. Semakin turun stabilitas antosianin mengakibatkan aktivitas antioksidan juga semakin rendah.

Garcia-Viguera dan Zafrilla (2001), menyatakan bahwa kehilangan antosianin antara $10 \%$ hingga $80 \%$ akan terjadi pada selai jika dipanaskan 
dengan rentangan antara $10-15$ menit. Sedangkan Sadilova dkk. (2006) menyatakan bahwa kerusakan sebanyak $50 \%$ antosianin buah elderberry akan terjadi bila dipanaskan pada suhu $95^{\circ} \mathrm{c}$ selama 3 jam. Beberapa peneliti juga telah menyebutkan bahwa suhu selama penyimpanan mempunyai efek logaritmik terhadap kerusakan antosianin (Drdak dan Daucik, 1990; Havlikova dan Mikova, 1985; Rhim, 2002)

\section{KESIMPULAN}

Berdasarkan penelitian dapat disimpulkan bahwa pelarut etanol dan air dengan rasio (100:0)) menghasilkan ekstrak antosianin kulit melinjo merah terbaik dengan rendemen $12,95 \%$, kadar total antosianin 43,52 $\mathrm{mg} / \mathrm{L}$ dan aktivitas antioksidan (penghambatan DPPH) 66,29\%. Ekstrak antosianin kulit merah antosianin stabil pemanasan 10-30 menit

\section{DAFTAR PUSTAKA}

Barros, L., Ferreira M.J., Quieros, B., Ferreira, I.C.F.R. dan Baptista, P. 2006. Total Phenols, Ascorbic Acid, $\beta$-carotene and Ltcopene in Portuguese Wild Edible Mushrooms and Their Antioxidant Activities. Food Chemistry. 103 (2007): 413-419.

Belitz, H.D. dan Grosch, W. 1987. Food Chemistry. Springer-Verlag, Berlin.

Devi, PS., Saravanakumar1, M. and Mohandas, S. 2012. The effects of temperature and $\mathrm{pH}$ on stability ofmanthocyanins from red sorghum (Sorghum bicolor) bran. African Journal of Food Science

6(24):

$567-573$

Devina, N., 2011. Optimasi Proses Ekstraksi Kulit Melinjo Merah (Gnetum gnemon L.) dan Pengaruh pH dan Cahaya terhadap Aktivitas Antioksidan. Fakultas Teknologi Industri, Universitas Pelita Harapan Kawaraci.

Drdak, M. dan Daucik, P. (1990). Changes of elderberry (Sambucus nigra) pigments during the production of pigment concentrates. Acta Aliment 19: 3-7.

Garc1'a-Viguera, C. dan Zafrilla, P. (2001). Changes in anthocyanins during food processing: influence on color, chemistry and physiology of selected food colorants. ACS Symposium Series 775 American

Chemical Society

Hanani, E., A. Mun'im dan R. Sekarini 2005. Identifikasi Senyawa Antioksidan dari Spons Callyspongin sp. Kep. Seribu. Majalah Ilmu Kefarmasian II(3).
Kunarto, B dan Pratwi, E. 2014 Mikroenkapsulasi Ekstrak Kulit Melinjo Merah (Gnetum gnemon L.) Dan Evaluasi Sifat Antioksidatifnya Pada Makanan Tradisional Berbasis Kelapa. Laporan Penelitian FTP, Universitas Semarang, Semarang

Moldovan, B., David, L., Chişbora, C. and Cimpoiu, C. 2012. Degradation kinetics of anthocyanins from european cranberrybush (Viburnum opulus L.) fruit extracts. effects of temperature, $\mathrm{pH}$ and storage Solvent. Molecules 17: 11655-11666

Mustafa, R.A., A.A. Hamid, S. Mohamed dan F. Abu Bakar. 2010. Total Phenolic Compounds, Flavonoids, and Radical Scavenging Activity of 21 Selected Tropical Plants. Journal of Food Science. 75 (1): C28-C35.

Sadilova, E., Stintzing, f.c. dan carle, R. (2006). Thermal

degradation of acylated and nonacylated anthocyanins.

Journal of Food Science 71: c504-c512

Sudarmadji, S., B. Haryono dan Suhardi. 1996. Prosedur Analissa Untuk Bahan Makanan dan Pertanian. Liberty Yogyakarta.

Suwito, F., 2011. Optimasi Aktivitas Antioksidan Kulit Melinjo Merah (Gnetum gnemon L.) terhadap Kombinasi $\mathrm{pH}$ dan Suhu. Jurusan Teknologi Pangan, Fakultas Teknologi Industri, Universitas Pelita Harapan Kawaraci.

Taie, H.A.A., R. El-Mergawi, R. dan S. Radwan. 2008. Isoflavonoid, flavonoid, phenolic acid, and antioxidant activity of soybean seeds as affected by organic and bioorganic fertilization. Journal of Agricultural and Environmental Science. 4 (2): 207-213

Zou Y., Y. Lu dan D. Wei. 2004. Antioxidant Activity of Flavonoid Rich Extract of Hypericum perforatum in Vitro. J. Agric. Food Chemistry 52:5032-5039. 